\title{
Development of Nonlinear Finite Element Models of Mortar-Free Interlocked Single Block Column Subjected to Lateral Loading
}

\author{
Furqan Qamar $^{1} \mathbb{D} \cdot$ Shunde Qin $^{2}$
}

Received: 23 November 2020 / Accepted: 11 April 2021 / Published online: 23 April 2021

(c) The Author(s) 2021

\begin{abstract}
Around the globe, the need for additional housing, due to the increase in world population, has led to the exploration of more cost effective and environmentally friendly forms of construction. Out of many technologies found, mortar-free interlocked masonry systems were developed to eliminate the deficiency of traditional masonry. For such systems against earthquakes, lateral resistance can be enhanced with plaster. But there is a need to further improve the performance of plaster in mortarfree interlocking walls for better ductility. The objective of this study is to develop nonlinear finite element (NLFE) models to explore the likely failure mechanism (e.g. bond failure) of such systems and to do parametric studies more cheaply than constructing many walls. Lateral failure load, load-displacement curves and crack patterns were compared with the experimental results. Parametric studies involving variation in block and plaster compressive strength and plaster thickness were undertaken using TNO DIANA NLFE models. A 150\% increase in thickness of plaster only resulted in $28 \%$ increase in failure load, and column thickness can be reduced to theoretical $25 \mathrm{~mm}$ of blocks with $8 \mathrm{~mm}$ of plaster and yet exceed the lateral strength of a 150-mm-thick unplastered column. A cost analysis was also carried out, based on NLFE models, and showed that fibrous plastered column with $25-\mathrm{mm}$-thickness blocks gave equivalent performance to the 150 -mm-thick unplastered column with $67 \%$ cost saving.
\end{abstract}

Keywords Nonlinear finite element $\cdot$ Interlocked single block $\cdot$ Lateral resistance $\cdot$ Fibrous plastering $\cdot$ Parametric $\cdot$ Cost analysis

\section{Introduction}

Masonry is a common term for a composite material made of various separate small elements (units) bonded together by some binding filler (mortar) or interlocked mechanisms for mortarless construction [1]. Historical masonry structures are, for a number of reasons, normally classified as low-strength and these masonry structures can be broadly divided into following three categories [2]:

- Masonry with poor mortar strength

- Masonry with poor unit strength

- Masonry with poor unit and mortar strength

Furqan Qamar

drfurqanqamar@warwickgrad.net

University of Warwick, Coventry, UK

2 WSP, Birmingham, UK
Masonry with poor mortar strength refers to structures where the unit/mortar interface governs the formation of cracks and collapse mechanism. Masonry with poor unit strength concerns structures where the strength of unit dominates mechanical behaviour. Tuff blocks are a prime example of this case. In the third case, the strength of mortar and unit are considered comparable and both have a major effect on failure mode. The type of material and bond strength affect the mechanical performance of the overall masonry structure [3]. Different experimental work was carried out in various studies to explore the effect of bond between masonry and plastering and concluded the high importance of bond in the strength of masonry [4]. Masonry walls are considered to be strong in resisting of vertical axial load [5], but there is often a need to improve their resistance when subjected to lateral load [6] such as wind and earthquake. Evaluation of the safety of masonry structures under seismic loading is a complex problem, and both linear and nonlinear methods have been used in different studies [7]. 
The finite element method is the most well-known analysis technique for elements subjected to static or dynamic loading. For a numerical model to effectively represent the behaviour of a real structure, both the constitutive model and the input material properties must be selected carefully. For this study, the computational software TNO DIANA was used for the application of the finite element method. For a masonry structure, FEM analysis can be performed using various modelling approaches. These include macroelement and micro-modelling approaches [8]. The most refined approach used by other researchers is micro-modelling [9]. Here different mechanical parameters and constitutive laws are used for different component parts. It allows for local failure of the units and of any bonding, so they can be modelled separately. In addition, it is possible to model the units with or without interfaces. Furthermore, to study structural failure cracking behaviour should be modelled accurately. Two types of cracking model are available to simulate behaviour numerically, which include the discrete crack and smeared crack models. The former introduces the crack to FE models manually by means of a separation between element edges [10]. The smeared crack approach does not track individual cracks but smears their effect over the FE by modifying its mechanical properties, as shown in Fig. 1 [11]. This approach is considered better than its discrete crack counterpart, which requires the mesh configuration to be updated as the cracks develop in the FE model. The smeared crack approach is further divided into two types: fixed smeared cracking and rotating smeared cracking approaches. With the former, the orientation of cracks remains fixed, which leads to an unrealistic and distorted crack pattern. With the rotating smeared crack approach, the orientation of the crack follows any change in the direction of principal tensile stresses. This gives results closer to the realistic value accepted by other studies [12].

Nonlinear finite element models have been developed in other studies of masonry structures using TNO DIANA. In some cases, FE models are used to simulate the behaviour of experimental work. Table 1 shows the outcome of the different studies and the details of the parameters explored. The scale of modelling varies from a single block to a masonry wall panel. Modelling was also used to identify the material
Fig. 1 Cracking concept: a discrete crack concept, $\mathbf{b}$ smeared crack concept

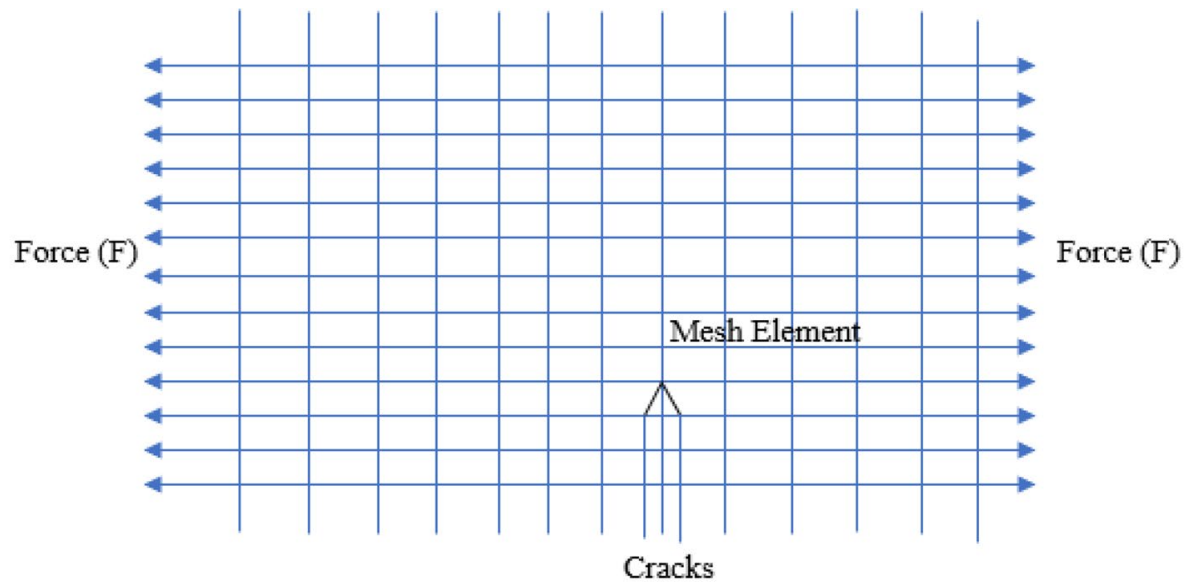

(a) Discrete Crack Concept

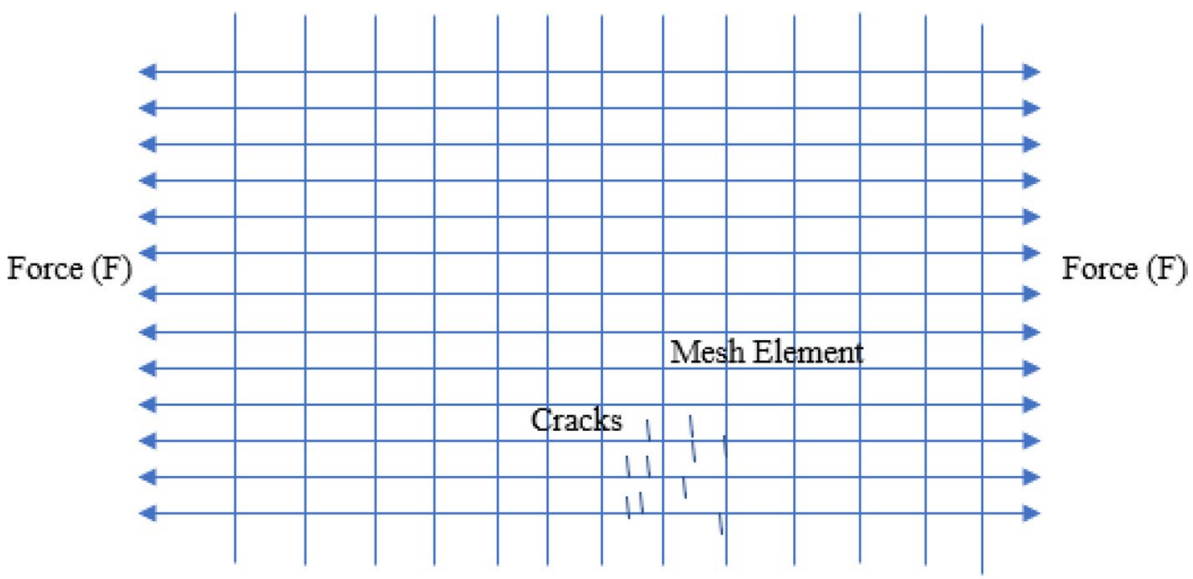

(b) Smeared Crack Concept 
Table 1 Comparison of numerical and experimental results from the literature

\begin{tabular}{lllll}
\hline Sample & Type of test & Parameters & $\begin{array}{l}\text { Numerical (experimen- } \\
\text { tal) outcome }\end{array}$ & \\
\hline Tuff masonry panel & Diagonal compression & Shear stress & $0.39 \mathrm{MPa}(0.38 \mathrm{MPa})$ & {$[14]$} \\
Adobe wall panel & Diagonal compression & Shear stress & $0.15 \mathrm{MPa}(0.14 \mathrm{MPa})$ & {$[1]$} \\
Hollow concrete block & Compression & Peak load & $550 \mathrm{kN}(600 \mathrm{kN})$ & {$[8]$} \\
Hollow clay units & Cyclic shear load & Shear capacity & $215 \mathrm{kN}(222 \mathrm{kN})$ & {$[15]$} \\
\hline
\end{tabular}

parameters for a masonry structure in the study by Sarhosis [13]. In Fig. 2, FE models developed in a variety of studies using TNO DIANA are shown.

In light of the outcome of previous studies micro-modelling, rotating smeared crack finite element modelling was chosen in this study to predict the lateral failure load of interlocked masonry. FE modelling of mortar-free interlocked block was also identified as a knowledge gap in the literature. The proposed FE modelling was validated by comparing peak load with the experimental lateral failure load, as explained in Sect. 3. These validated NLFE models are used to carry out the parametric study of different parameters including block and plaster compressive strength and plaster thickness rather than constructing various experimental columns/walls.

\section{Modelling Methodology}

\subsection{Geometry}

The geometry of the experimental tests was reproduced by modelling blocks and interlocked mechanism with interface elements between them representing a mortar-free interlocked block column as shown in Fig. 3. Seven models were produced as detailed in Table 2 .

The block size was $300 \mathrm{~mm} \times 150 \mathrm{~mm} \times 100 \mathrm{~mm}$ with a gap of $10 \mathrm{~mm}$ representing the interlock between the blocks. 15 blocks were modelled representing a 1590-mmhigh column. The selection of element types, and of material cracking and plasticity models, has already been successfully employed in other studies $[14,17]$ and are applied

\begin{tabular}{|l|l|l}
\hline Model & Modelling approach & Reference \\
\hline & $\begin{array}{l}\text { Micro-modelling smeared crack approach } \\
\text { representing the tuff and the mortar independently }\end{array}$ & {$[13]$} \\
\hline & $\begin{array}{l}\text { Masonry wall panel using micro -modelling approach } \\
\text { with brick and mortar without interface. }\end{array}$ & {$[1]$} \\
\hline & $\begin{array}{l}\text { Macro-modelling approach unreinforced masonry } \\
\text { panel for diagonal compression testing. }\end{array}$ & {$[14]$} \\
\hline & $\begin{array}{l}\text { Smeared crack approach for sisal reinforced concrete } \\
\text { block. }\end{array}$ & {$[8]$} \\
\hline
\end{tabular}

Fig. 2 FE models developed by other researchers 


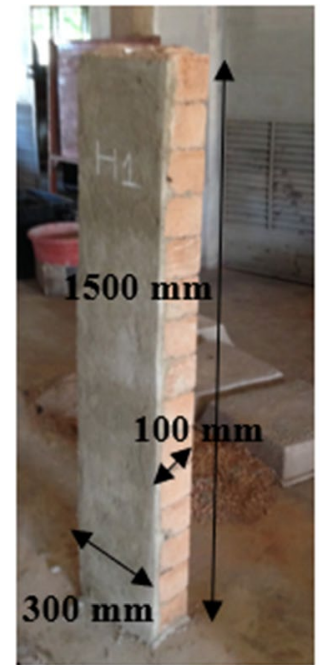

(a)

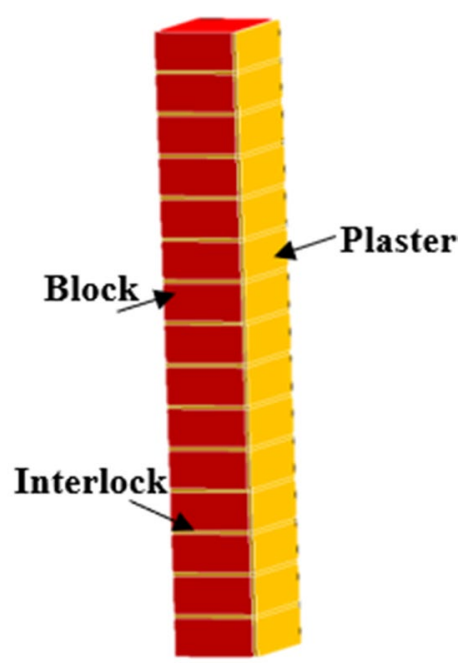

(b)
Fig. 3 Geometry of interlocked masonry column a experimental view, $\mathbf{b}$ TNO DIANA view

Table 2 Labelling of TNO DIANA models

\begin{tabular}{ll}
\hline Combinations & Model symbol \\
\hline Block-only unplastered & $\mathrm{M} 1-(\mathrm{U})$ \\
8-mm-thick plain-plastered column & $\mathrm{M}$ - $-(\mathrm{P}, 8, \mathrm{~N})$ \\
20-mm-thick plain-plastered column & $\mathrm{M}$ - $-(\mathrm{P}, 20, \mathrm{~N})$ \\
8-mm-thick rice-straw-plastered column & $\mathrm{M} 4-(\mathrm{P}, \mathrm{R}, 8)$ \\
20-mm-thick rice-straw-plastered column & $\mathrm{M} 5-(\mathrm{P}, \mathrm{R}, 20)$ \\
8-mm-thick sisal-plastered column & $\mathrm{M} 6-(\mathrm{P}, \mathrm{S}, 8)$ \\
20-mm-thick sisal-plastered column & $\mathrm{M} 7-(\mathrm{P}, \mathrm{S}, 20)$ \\
\hline
\end{tabular}

Table 3 Number of elements for the TNO DIANA models based on mesh sizes

\begin{tabular}{lllll}
\hline Model & $\begin{array}{l}\text { Block } \\
\text { elements } \\
\text { no }\end{array}$ & $\begin{array}{l}\text { Block inter- } \\
\text { face elements } \\
\text { No }\end{array}$ & $\begin{array}{l}\text { Plaster inter- } \\
\text { face elements } \\
\text { no }\end{array}$ & $\begin{array}{l}\text { Plaster } \\
\text { elements } \\
\text { no }\end{array}$ \\
\hline M1-(U) & 2400 & 520 & - & - \\
M2-(P,8,N) & 2400 & 520 & 640 & 1480 \\
M3-(P,20,N) & 2400 & 520 & 640 & 3700 \\
M4-(P,R,8) & 2400 & 520 & 640 & 1480 \\
M5-(P,R,20) & 2400 & 520 & 640 & 3700 \\
M6-(P,S,8) & 2400 & 520 & 640 & 1480 \\
M7-(P,S,20) & 2400 & 520 & 640 & 3700 \\
\hline
\end{tabular}

in this study. A regular and dense discretisation was used based on the HX24L eight-node isoparametric solid brick element which was successfully used by other studies [16, 17]. Table 3 details the no. of elements used for different models. In TNO DIANA, these elements are represented by eight-node brick elements with three translational degrees of freedom at each node. Mesh arrangement average dimensions of $30 \mathrm{~mm}, 25 \mathrm{~mm}$ and $37.5 \mathrm{~mm}$ in $x, y$ and $z$ directions, respectively, have been used for meshing the blocks. For the plaster, $30 \mathrm{~mm}, 25 \mathrm{~mm}$ and $4 \mathrm{~mm}$ in $x, y$ and $z$ directions, respectively, have been used, as per previous studies [14, $16,17]$. Figure 4 shows the adopted mesh size of the proposed FE models. Different meshing sizes were examined as explained in Sect. 3.4, and the selected mesh size gave a good agreement between the output of finite element models and experimental results for unplastered column.

\subsection{Material and Interface Properties}

\subsubsection{Block Properties}

The compressive strength $\left(f_{\mathrm{c}}\right)$ and Young's modulus $(E)$ were derived from uniaxial compression tests of mortarfree interlocking block samples as detailed in the work by Qamar [18]. The tensile strength of a masonry unit is difficult to obtain from any direct relationship to its compressive strength. This is because of variation in the shapes, material and method of manufacturing of masonry blocks. An extensive testing was carried out by [19] for the tensile strength of clay units and proposed a ratio between the tensile and compressive strength which ranges from 0.30 to 0.10 . A 0.10 ratio between tensile and compressive strength was used in this study to best match the experimental findings. The block properties used in the model are detailed in Table 4.

For block material properties, constitutive models proposed by another researcher [16] were used, based on a smeared-crack approach, assuming exponential strain softening in tension and plasticity in compression. Parabolic curve formulations, based on tensile and compressive fracture energy, are shown in Fig. 5.

The validation of models with the experiment values, as demonstrated in Sect. 3, was obtained by using a Poisson's ratio of 0.15 . The same Poisson's ratio was also used by several researchers, such as $[17,19]$. The fracture energy $\left(G_{\mathrm{f}}\right)$ was related to compressive strength by Eq. 1, as was used and proposed by different researchers [20,21]. Equation 1 is a fracture energy model which is frequently used to study the concrete behaviour. No fracture energy model is available for masonry in the literature studied. Hence, Eq. 1 has been adopted. However, it was found that the FE results for the control column are in good agreement with the experimental results when using this model as detailed in Sect. 3. Consequently, the same model has been used for other FE models.

$G_{\mathrm{f}}=\left(43.2+1.13 f_{\mathrm{cu}}\right) * 10^{3}$

$G_{\mathrm{f}}$, fracture energy $(\mathrm{N} / \mathrm{mm}) ; f_{\text {cu }}$, compressive strength of blocks (MPa). 
Fig. 4 TNO DIANA analysis, adopted mesh a $X$-view, b $Z$-view

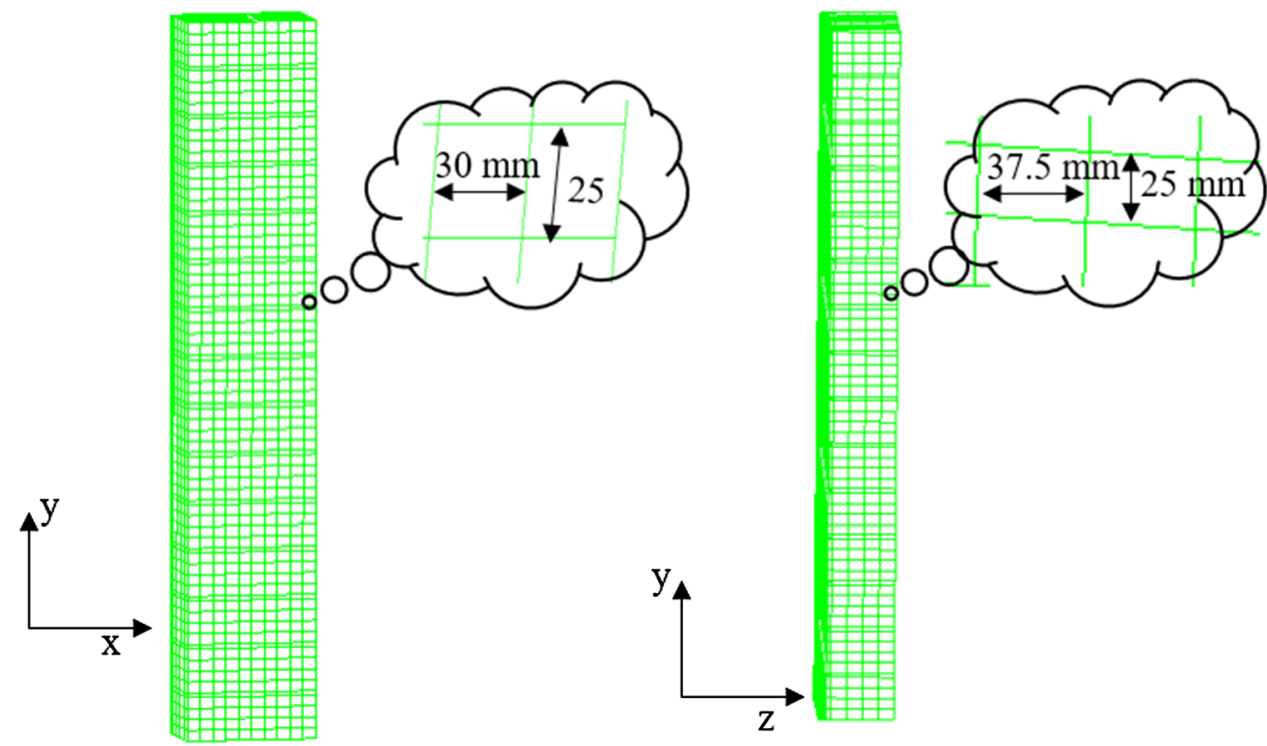

(a)

(b)
Table 4 Block properties used in the models

\begin{tabular}{llllll}
\hline Material & $\begin{array}{l}\text { Modulus } \\
\text { of elastic- } \\
\text { ity } E \\
(\mathrm{MPa})\end{array}$ & $\begin{array}{l}\text { Poison's } \\
\text { ratio } n\end{array}$ & $\begin{array}{l}\text { Com- } \\
\text { pressive } \\
\text { strength } f_{\mathrm{c}} \\
(\mathrm{MPa})\end{array}$ & $\begin{array}{l}\text { Tensile } \\
\text { strength } f_{\mathrm{t}} \\
(\mathrm{MPa})^{*}\end{array}$ & $\begin{array}{l}\text { Fracture } \\
\text { energy } G_{\mathrm{f}} \\
(\mathrm{N} / \mathrm{mm})\end{array}$ \\
\hline Block & 201 & 0.15 & 0.83 & 0.080 & 0.0441 \\
\hline
\end{tabular}

*Taken as $0.1 * f_{\mathrm{c}}$

\subsubsection{Block Interface Properties}

The interlocked mechanism of ISSB (Interlocked soil stabilised block) was modelled using 8-node bond slip interface elements between the blocks. Both friction-based and perfect bond models were studied, and it was found that a frictionbased model gave a better match with experimental findings. A friction-based model is based on the resistance being proportional to the self-weight of the block. In the frictionbased model as shown in Fig. 6, a yield shear stress is calculated for each course of the blocks in the wall depending on their weight. A value for the coefficient of friction was obtained by using hit and trial method. A maximum slip (F2) was assumed as $150 \mathrm{~mm}$, based on the width of the block. $\mathrm{F} 1$ and $\mathrm{S} 1$ are representing the starting point of slip-displacement constitutive model. It means no slip is expected, when no force is applied. Equation 2 is used to calculate the interface properties at each layer of the blocks. The values of block interlocked interface properties are shown in Table 5 .

peak bond stress $=\mu * n * W_{b} / a_{b}$

where $\mu$, coefficient of friction; $n$, number of blocks; $w_{\mathrm{b}}$, weight of block; $a_{\mathrm{b}}$, area of block.

\subsubsection{Plaster Properties}

The compressive strength $\left(f_{\mathrm{c}}\right)$ and Young's modulus $(E)$ were derived from uniaxial compression tests of plaster cube samples as detailed in the work by [18]. Fracture energy values in Table 6 are obtained from Eq. 1, and tensile strength is taken as $0.1 * f_{\mathrm{c}}$. The same constitutive model was used for the plaster as explained above in the block properties section. The values of the material properties used in this study are detailed in Table 6.

\subsubsection{Properties of the Interface Between Block and Plaster}

Plaster to block interface was modelled with 8-node bondslip interface elements. In this model, it was considered that bond failure occurs within a thin layer of block adjacent to the interface of plaster-to-block, because the plaster is usually stronger than the block. The bond-slip models, which were developed by [22], were used in this study, and values are calculated based on Eqs. 3-6 and detailed in Table 7. Hence, the bond-slip model displays the overall behaviour of the block-to-plaster interface, rather than the plaster or block material. Bond-slip model was proposed by [22]:

$$
\begin{gathered}
\tau_{\text {peak }}=\left(54 f_{\mathrm{c}}^{\prime}\right)^{0.19} \\
S_{\text {peak }}=0.057 \sqrt{G_{\text {fi }}}
\end{gathered}
$$

$S_{\mathrm{u}}=\frac{2 G_{\mathrm{fi}}}{\tau_{\text {peak }}}$ 

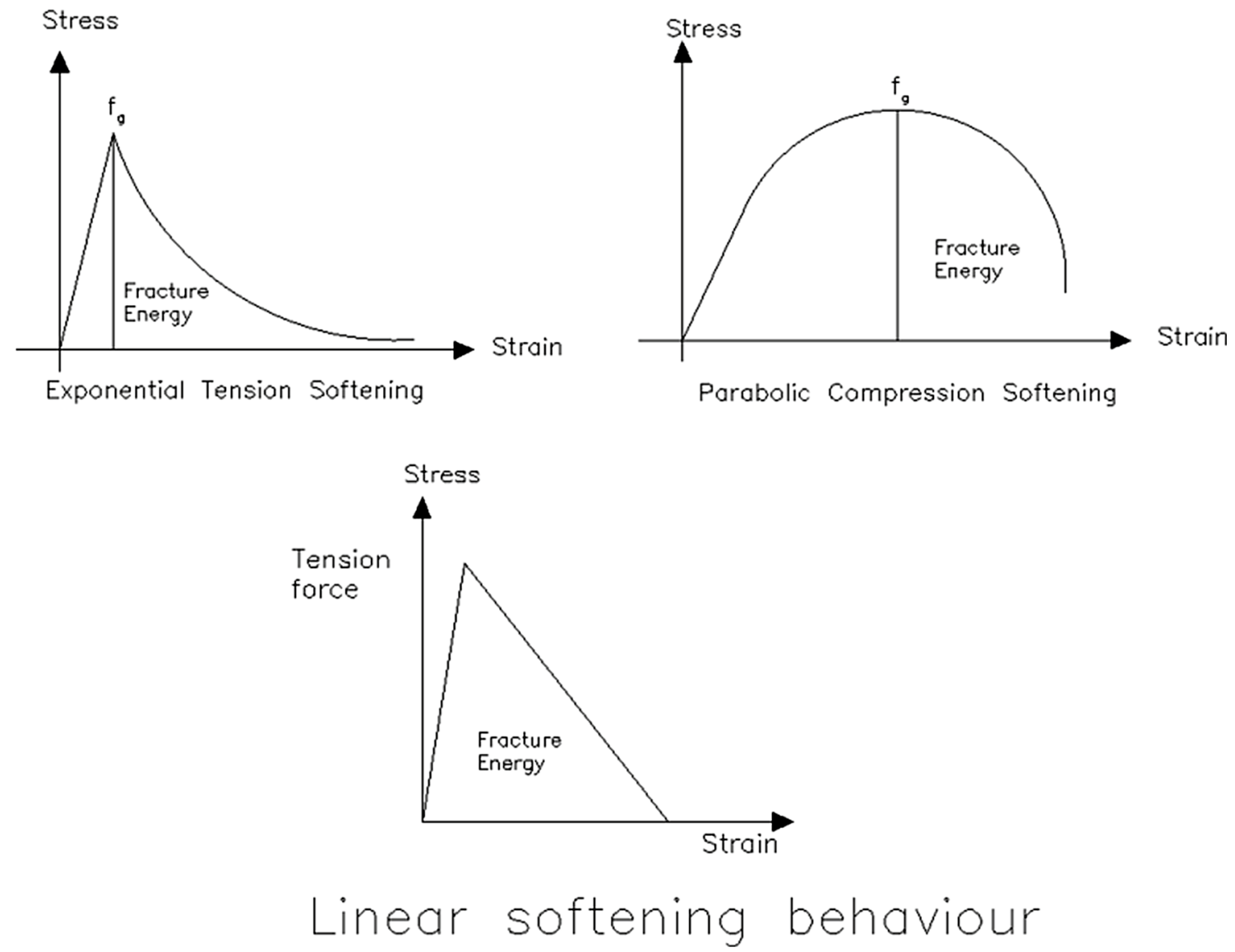

Fig. 5 Material model used in TNO DIANA

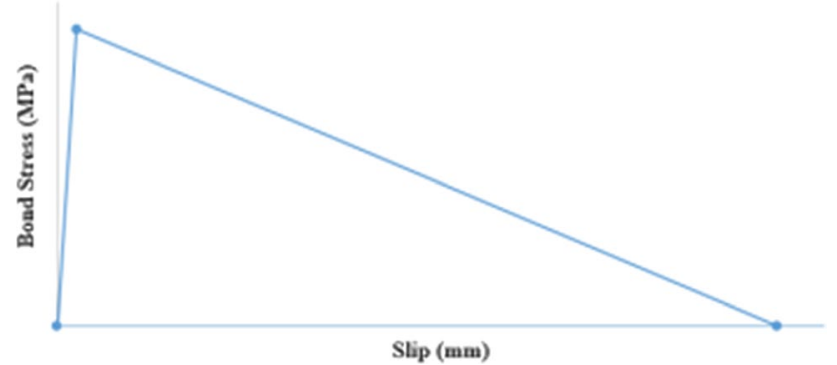

Fig. 6 Friction-based bond slip model for the interface between block and plaster

$G_{\mathrm{fi}}=\left(\frac{\tau_{\text {peak }}}{6.6}\right)^{2}$

where $\tau_{\text {peak }}$, the peak bond stress $\left(\mathrm{N} / \mathrm{mm}^{2}\right) ; f_{\mathrm{c}}^{\prime}$, compressive strength of plaster $\left(\mathrm{N} / \mathrm{mm}^{2}\right) ; S_{\text {peak }}$, slip corresponding to the peak bond stress $(\mathrm{mm}) ; S_{\mathrm{u}}$, ultimate slip $(\mathrm{mm}) ; G_{\mathrm{fi}}$, interfacial fracture energy $(\mathrm{N} / \mathrm{mm})$.

The above equations, based on bond-slip model, consider bond stress-slip linear relation up to the peak bond stress. The separation of block and plaster interface starts if the slip exceeds the limiting value, the slip value related to the peak bond stress. This process is based on linear softening behaviour, as shown in Fig. 5. In this research, this model was adopted as it gave a better agreement between the FE predictions and the experimental result, as validated in Sect. 3.

\subsection{Loading Applied}

Out-of-plane loading was applied in this analysis corresponding to unit displacement applied at the nodes corresponding to $1000 \mathrm{~mm}$ height of masonry column as per experimental work. The experimental work and the results are detailed in the work by [23]. A displacement loading method was used for the modelling as this can predict the post-failure behaviour of the columns (in a way not possible in the laboratory). This method was also successfully used by the other researchers [16, 24]. 
Table 5 Block interlocked interface properties used in the models

\begin{tabular}{llllllll}
\hline Model & $\mathrm{Df}_{11}\left(\mathrm{~N} / \mathrm{mm}^{3}\right)$ & $\mathrm{Df}_{22}\left(\mathrm{~N} / \mathrm{mm}^{3}\right)$ & $\mu$ & $S_{1}(\mathrm{MPa})$ & $F_{1}(\mathrm{~mm})$ & $S_{2}(\mathrm{MPa})$ & $F_{2}(\mathrm{~mm})$ \\
\hline M1-(U) & 0.02 & 0.20 & 0.1 & 0 & 0 & $3.488 \mathrm{E}-07$ & 150 \\
M2—(P,8,N) & 0.02 & 0.20 & 0.1 & 0 & 0 & 0.0001744 & 150 \\
M3- $\mathrm{P}, 20, \mathrm{~N})$ & 0.01 & 0.1 & 0.1 & 0 & 0 & 0.0001744 & 150 \\
M4-(P,R,8) & 0.0021 & 0.021 & 0.1 & 0 & 0 & 0.0001744 & 150 \\
M5-(P,R,20) & 0.0015 & 0.015 & 0.1 & 0 & 0 & 0.0001744 & 150 \\
M6-(P,S,8) & 0.0021 & 0.021 & 0.1 & 0 & 0 & 0.0001744 & 150 \\
M7— (P,S,20) & 0.00035 & 0.0035 & 0.1 & 0 & 0 & 0.0001744 & 150 \\
\hline
\end{tabular}

where $\mathrm{Df}_{11}=$ normal linear stiffness modulus; $\mathrm{Df}_{22}=$ shear linear stiffness modulus; $\mu=$ coefficient of friction; $S_{1}=$ peak bond stress; $F_{1}=$ slip corresponding to peak bond stress; $S_{2}=$ yield stress; $F_{2}=$ Maximum slip

\begin{tabular}{llllll}
\hline Material & $\begin{array}{l}\text { Modulus of } \\
\text { elasticity } E \\
(\mathrm{MPa})\end{array}$ & Poison's ratio $n$ & $\begin{array}{l}\text { Compressive } \\
\text { strength } f_{\mathrm{c}} \\
(\mathrm{MPa})\end{array}$ & $\begin{array}{l}\text { Tensile } \\
\text { strength } f_{\mathrm{t}} \\
(\mathrm{MPa})^{*}\end{array}$ & $\begin{array}{l}\text { Fracture } \\
\text { energy } G_{\mathrm{f}}(\mathrm{N} / \\
\mathrm{mm})\end{array}$ \\
\hline Plain plaster & 2990 & 0.15 & 19.33 & 1.933 & 0.065 \\
Rice straw plaster & 2483 & 0.15 & 8.67 & 0.867 & 0.053 \\
Sisal plaster & 7175 & 0.15 & 19.88 & 1.988 & 0.657 \\
\hline
\end{tabular}

*Taken as $0.1 * f_{\mathrm{c}}$

\begin{tabular}{lcclllc}
\hline Model & $\mathrm{Df}_{11}\left(\mathrm{~N} / \mathrm{mm}^{3}\right)$ & $\mathrm{Df}_{22}\left(\mathrm{~N} / \mathrm{mm}^{3}\right)$ & $\tau_{\text {peak }}\left(\mathrm{N} / \mathrm{mm}^{2}\right)$ & $S_{\text {peak }}(\mathrm{mm})$ & $S_{\mathrm{u}}(\mathrm{mm})$ & $G_{\text {fi }}(\mathrm{N} / \mathrm{mm})$ \\
\hline M1-(U) & - & - & - & - & - & - \\
M2-(P,8,N) & 157.8 & 1577.9 & 3.590 & 0.164 & 0.031 & 0.295 \\
M3-(P,20,N) & 157.8 & 1577.9 & 3.590 & 0.164 & 0.031 & 0.295 \\
M4-(P,R,8) & 157.8 & 1577.9 & 3.082 & 0.141 & $2.66 \mathrm{E}-02$ & 0.218 \\
M5-(P,R,20) & 157.8 & 1577.9 & 3.082 & 0.141 & $2.66 \mathrm{E}-02$ & 0.218 \\
M6-(P,S,8) & 157.8 & 1577.9 & 3.609 & 0.165 & 0.031 & 0.299 \\
M7-(P,S,20) & 157.8 & 1577.9 & 3.609 & 0.165 & 0.031 & 0.299 \\
\hline
\end{tabular}

Table 7 Plaster and block interface properties used in the models
Table 6 Material properties for plaster used in TNO DIANA

\subsection{Constraint Condition}

The bases of the columns were considered fixed and represented by a fixed constraint in the model. The effect of base constraints should be explored in further studies. For experimental work, plain concrete was used at the base of the columns as shown in Fig. 7.

\subsection{Solution Method}

To attain convergence in the analysis of failure load, an incremental iterative process was adopted by increasing displacement by $0.1 \mathrm{~mm}$ for 20 steps. The Secant iteration method was used, to achieve balance at each step. Similar procedures were adopted by [12]. Based on [25, 26], a displacement norm value of $0.05,0.2$ and 0.9 for block, plain plaster and fibrous plaster models, respectively, was adopted to specify convergence critical. A maximum of 1000,000 iterations was allowed at each step before termination of the analysis in the case of non-convergence; however, in all models convergence was achieved before reaching the iteration limit. This approach proved successful, as convergence was achieved at every load step for the block-only, plain-plastered and fibrous-plastered FE models. The output reports showed that convergence was met at each load analysis step. The values used are presented in Table 8 .

\section{Results and Validation}

In this section, the results of the comparison between the finite element model output and the experimental work are presented. The comparative study was undertaken to determine the validity of the finite element models in predicting the nonlinear behaviour of the unplastered, plain-plastered and fibrous-plastered columns. Failure load, maximum 
displacement, stiffness and cracking patterns are compared in Sects. 3.1, 3.2 and 3.3, respectively. The results of the comparative study between FE models and experimental works are presented with the help of graphs and tables.

\subsection{Maximum Load}

The experimental results of failure load $F_{\text {exp }}$ and the FE predicted values $F_{\text {Diana }}$ for all specimens are presented in
Table 9. The FE predicted value is the maximum force which can be calculated as the sum of the reactions at the point of application of loading. The FE prediction values were in good agreement with the experimental results for all cases within $13 \%$ difference. The proposed FE models for all cases underestimated failure load with a maximum mean experimental/FE ratio of 1.07 for plain-plastered models. The rotating crack model assumes that cracking always occurs within principal planes, and it does not consider internal
Fig. 7 Constraint condition for the columns in the model and experimental work
Table 8 Mesh sizes and solver for the TNO DIANA models

Table 9 Comparison of experimental and numerical results
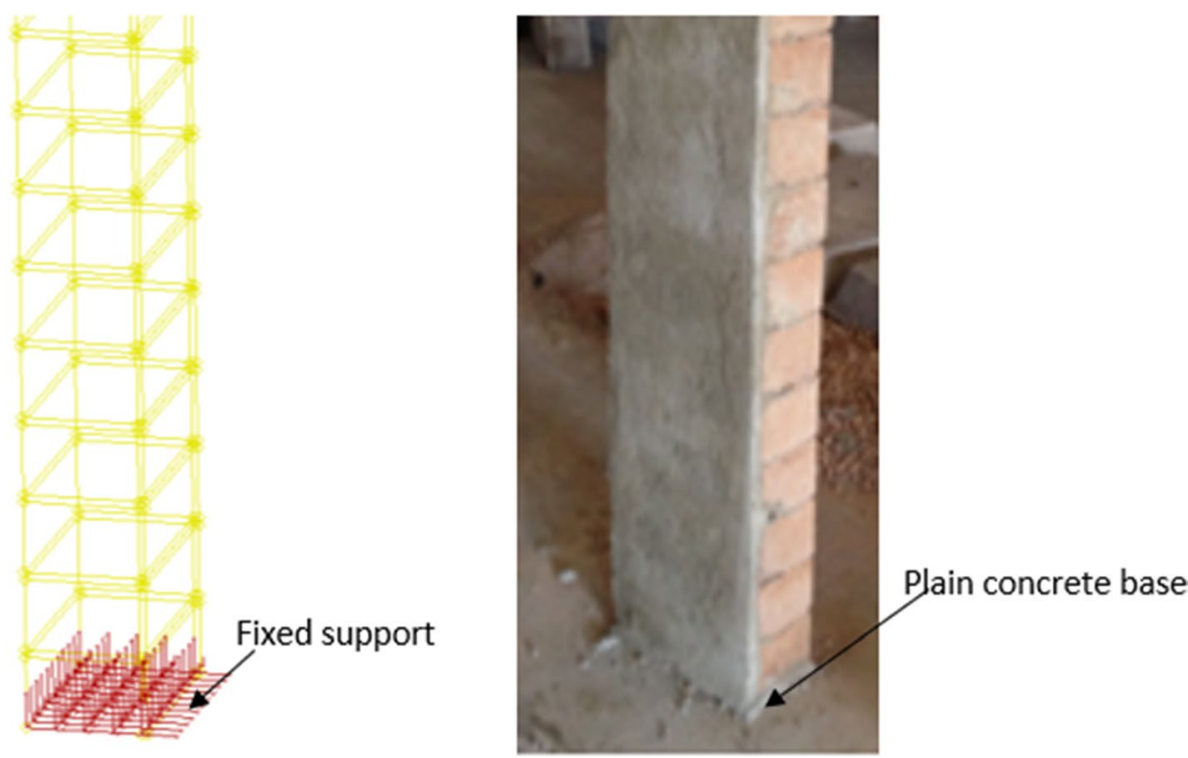

\begin{tabular}{llllll}
\hline Model & Size (step) $\mathrm{mm}$ & Tolerance mm & $\begin{array}{l}\text { Nonlinear } \\
\text { analysis } \\
\text { method }\end{array}$ & Max no. of Iterations & $\begin{array}{l}\text { Convergence } \\
\text { critical mm }\end{array}$ \\
\hline M1-(U) & $0.1(20)$ & $1.00 \mathrm{E}-6$ & Secant & $1,000,000$ & 0.05 \\
M2—(P,8,N) & $0.1(20)$ & $1.00 \mathrm{E}-6$ & Secant & $1,000,000$ & 0.2 \\
M3-(P,20,N) & $0.1(20)$ & $1.00 \mathrm{E}-6$ & Secant & $1,000,000$ & 0.2 \\
M4-(P,R,8) & $0.1(20)$ & $1.00 \mathrm{E}-6$ & Secant & $1,000,000$ & 0.9 \\
M5-(P,R,20) & $0.1(20)$ & $1.00 \mathrm{E}-6$ & Secant & $1,000,000$ & 0.9 \\
M6- (P,S,8) & $0.1(20)$ & $1.00 \mathrm{E}-6$ & Secant & $1,000,000$ & 0.9 \\
M7- (P,S,20) & $0.1(20)$ & $1.00 \mathrm{E}-6$ & Secant & $1,000,000$ & 0.9 \\
\hline
\end{tabular}

\begin{tabular}{llllc}
\hline Model & $\begin{array}{l}\text { Experimental lateral peak/ } \\
\text { failure load }\left(F_{\text {exp }}\right)(N)\end{array}$ & $\begin{array}{l}\text { TNO DIANA lateral peak/ } \\
\text { failure load }\left(F_{\text {DIANA }}\right)(N)\end{array}$ & $\begin{array}{l}\text { Ratio } \\
F_{\text {exp }} / F_{\text {DIANA }}\end{array}$ & Average \\
\hline M1- $(\mathrm{U})$ & 15 & 14.8 & 1.01 & 1.01 \\
M2-(P,8,N) & 48 & 42.2 & 1.13 & 1.07 \\
M3- (P,20,N) & 75 & 74.57 & 1.00 & \\
M4-(P,R,8) & 238 & 242.5 & 0.98 & 1.00 \\
M5-(P,R,20) & 256 & 247.9 & 1.03 & \\
M6- (P,S,8) & 242 & 232.2 & 1.04 & 1.04 \\
M7- (P,S,20) & 312 & 289.3 & 1.04 & \\
\hline
\end{tabular}


shear contribution across the crack plane. Therefore, it was expected to obtain a lower value of failure load from FE models than the experimental value. The only exception was found for the $8-\mathrm{mm}$ rice straw plastered model where the experimental/FE ratio was 0.98 . The reason for this is due to assumed values of block interface properties due to a lack of experimental data. Figure 8 shows the comparison of the results for both experimental and FE analysis. The ranges at the top of bars represent variability in the experimental result.

\subsection{Load-Displacement Curves}

Figure 9a-g shows load-displacement curves for the results of experimental and FE analysis. Results of seven different FE models, listed in Table 2, were compared with the corresponding experimental results. For unplastered columns, the FE results showed good agreement with the experimental load-displacement graph, showing similar peak load and stiffness. The load-displacement curves can be divided into two stages, i.e. loading up to first-crack and further loading up to failure. Comparing the first stage, it was observed that the stiffness of the FE model was higher than the experimental work in general for fibrous plaster columns. Minor cracks are normally formed during the setting time of plaster and are known as shrinkage cracks. An increase in the applied lateral load spreads these minor cracks and steadily forms a bigger, more visible crack. However, the FE model was based on using the smeared crack method, which means that cracks due to shrinkage were not captured. Therefore, the stiffness of the FE models was higher than the experimental tests in the first stage of crack formation for fibrous plaster columns. Comparing the displacement of the experimental results and FE predicted values, it can be seen that the FE models accurately projected the displacement in general for all cases. Post-peak-load behaviour was not compared with FE models as there were not enough data available from the experimental results.

\subsection{Crack Pattern}

FE analysis has the capacity to show the development of cracks which is considered as one of the merits of using such analysis. Figure 10 shows the comparison between experimental and FE model crack patterns at failure for unplastered, plain-plastered and fibrous-plastered samples. The FE models crack pattern is presented by the crack contour plots. It can be seen that the FE model adequately projected the failure cracks of unplastered sample, which showed the stress concentration with red contours at the base and the opening of interlock at tension face, as shown in experimental results.

Similarly, for plain and fibrous samples, FE predicted the cracks within block and plaster interface showing resemblance to the experimental results. The difference between the plain-plastered and fibrous-plastered samples can be observed with showing fewer cracks in the plain-plastered FE model as shown in Fig. 10b, whereas the fibrous-plastered sample showed more cracks as is visible in Fig. 10c. This ties in well with the outcome of the experimental work as fibrous plastered samples showed more ductility due to the presence of the fibres.

This resulted in the ductile failure of the fibrous plastered samples as compared to the brittle failure for all other samples. It can also be observed that failure of plain- and fibrous-plastered samples occurred due to cracking in the interface between the block and plaster rather than within the block. Similar behaviour was noted in FE models where
Fig. 8 Failure load comparison between TNO DIANA model and experimental results

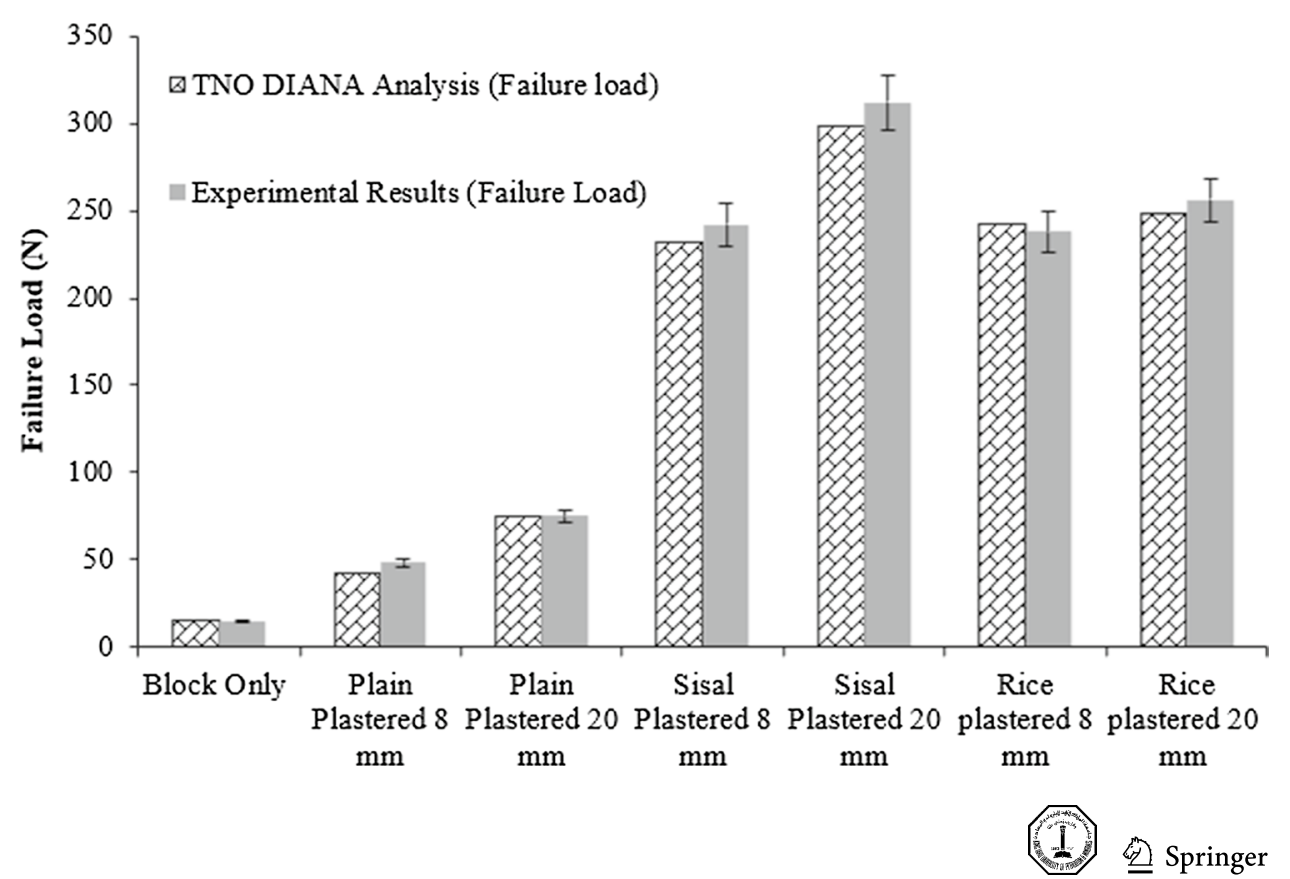


Fig. 9 Comparison of loaddisplacement graphs between TNO DIANA and experimental results a block-only, b plain-plastered $8 \mathrm{~mm}, \mathbf{c}$ plain-plastered $20 \mathrm{~mm}$, d ricestraw-reinforced plaster $8 \mathrm{~mm}$, e rice-straw-reinforced $20 \mathrm{~mm}$, f sisal-plastered $8 \mathrm{~mm}$ and $\mathbf{g}$ sisal-plastered $20 \mathrm{~mm}$

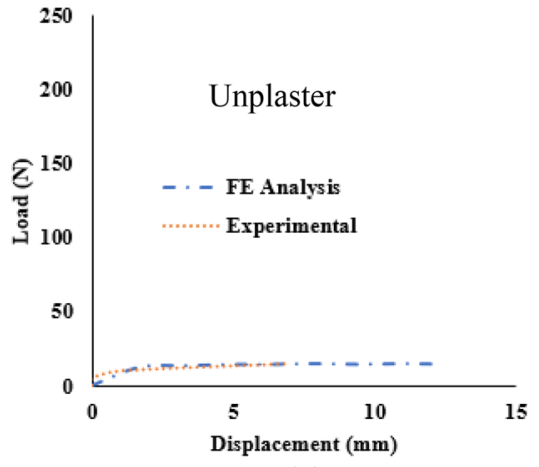

(a)

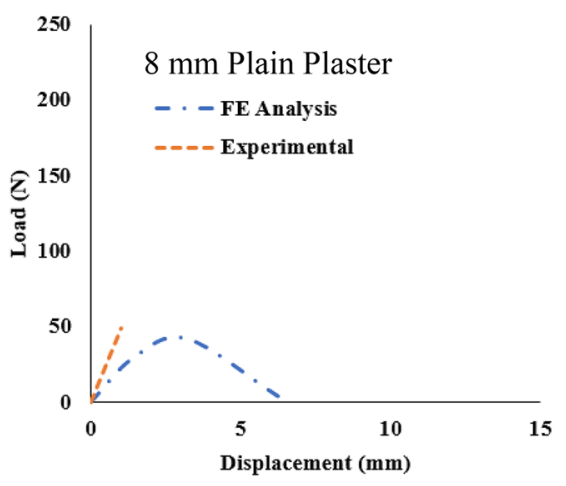

(b)

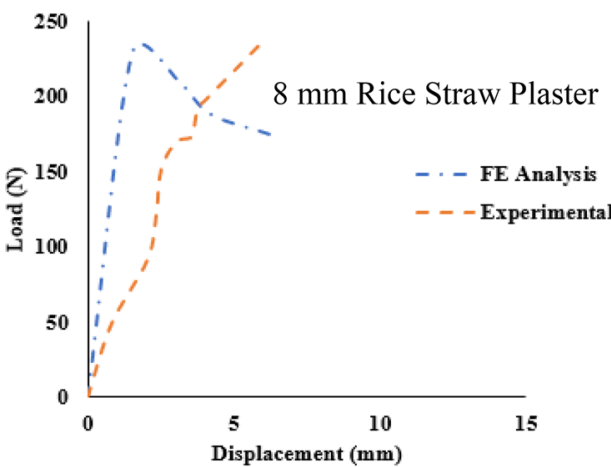

(d)

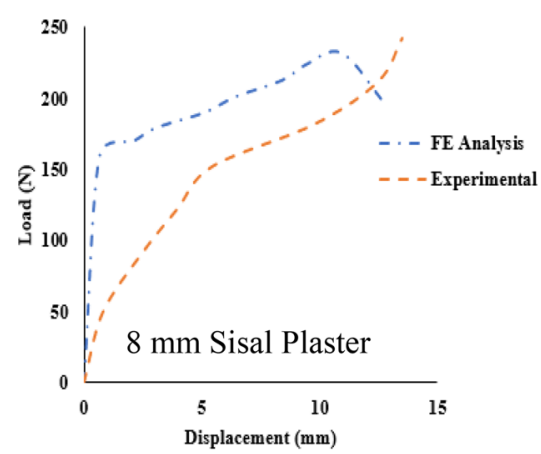

(f)

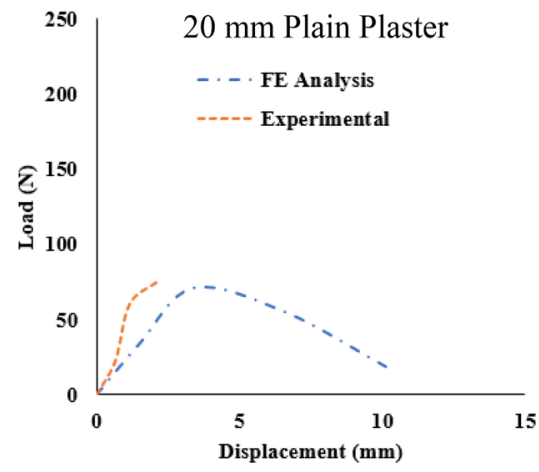

(c)

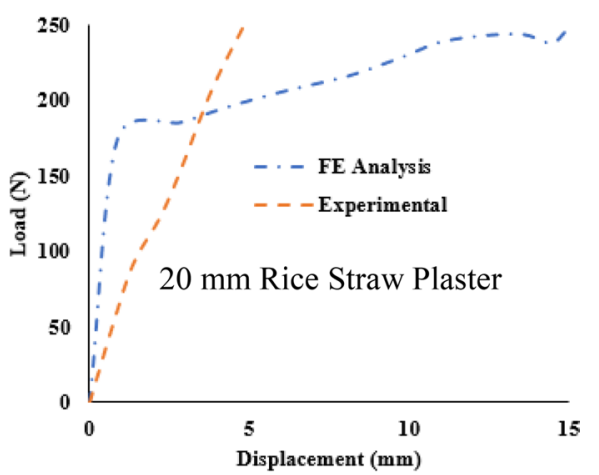

(e)

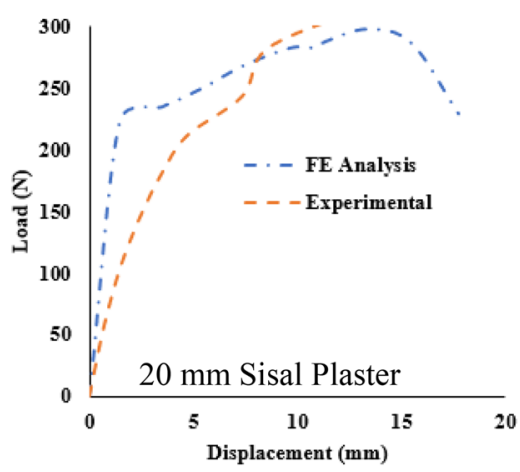

(g) 
Fig. 10 Crack pattern comparison experimental and TNO DIANA a unplastered; b plainplastered; c fibrous-plastered
TNO DIANA Crack Pattern

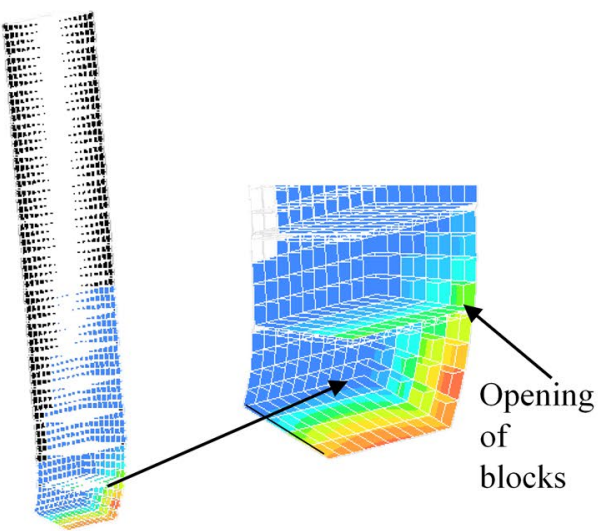

(a)

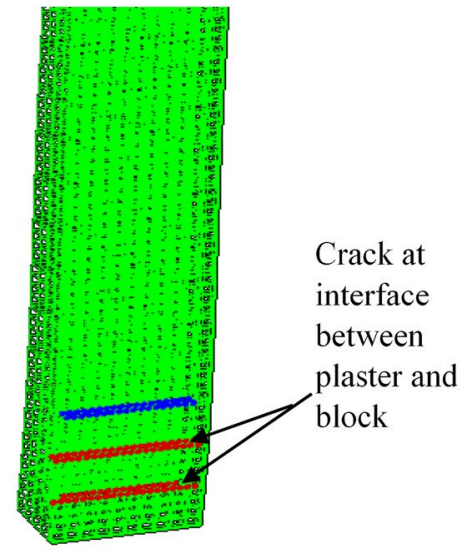

(b)
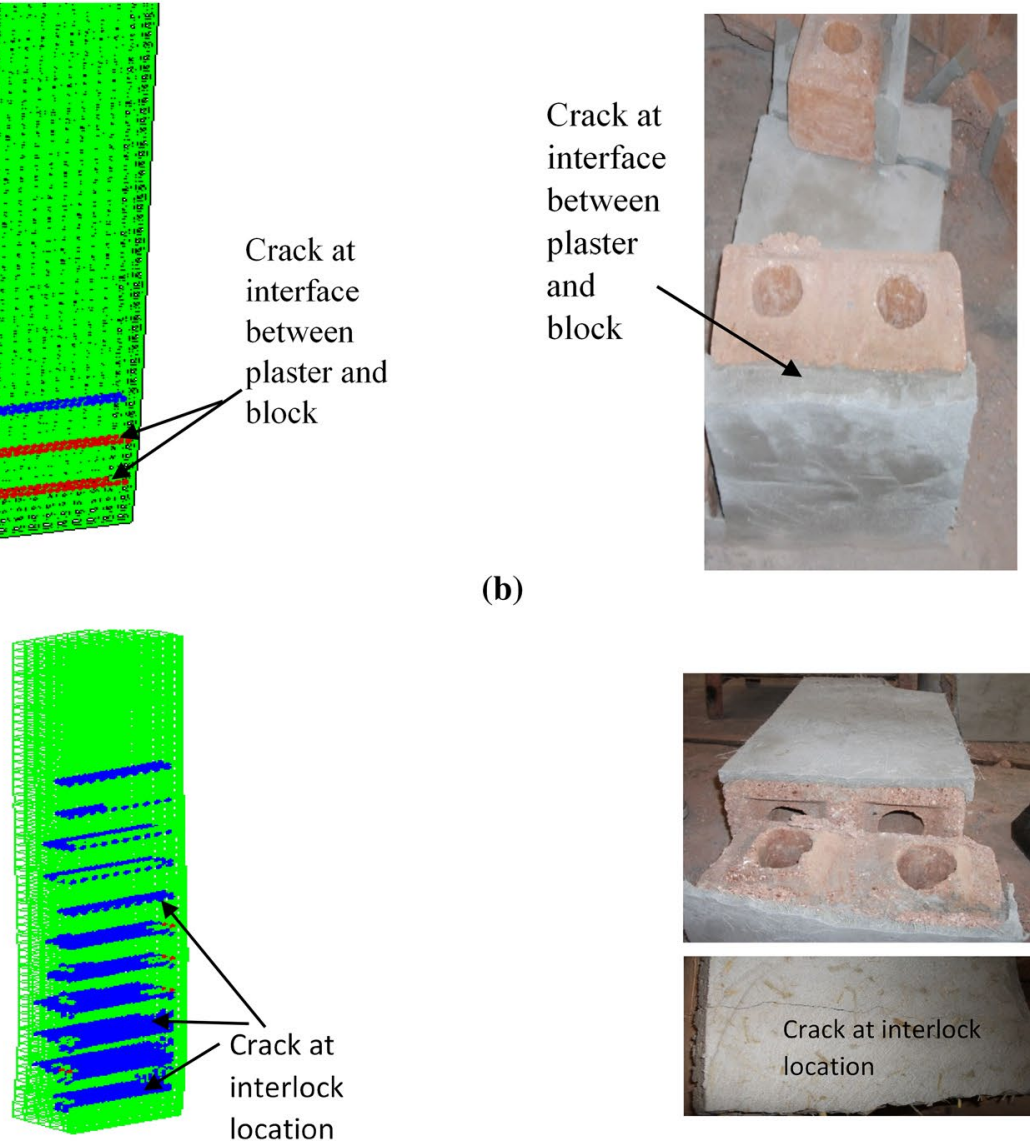

Experimental Crack Pattern

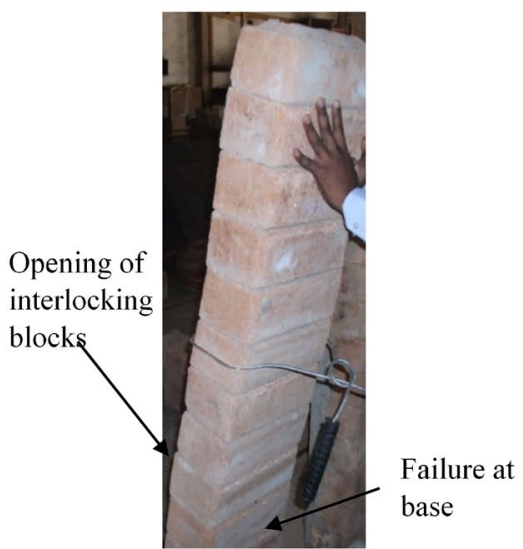

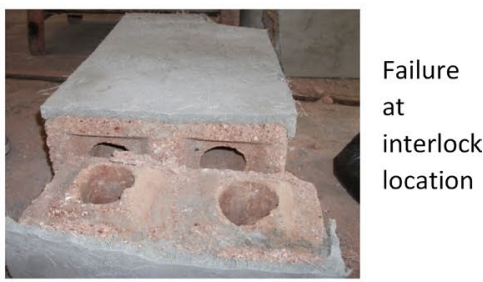

Crack at interlock location

(c)

cracks were initiated within the interface between block and plaster.

\subsection{Sensitivity Analysis}

In this section, sensitivity analyses for the parameters of the FE model are discussed: these include the block mesh size and the block and plaster tensile strengths. Both of these were found to be critical in predicting the results from $\mathrm{FE}$ as compared to experimental value. Mesh size is a modelling variable which influences the FE results; therefore, a sensitivity analysis was carried out to find the most suitable mesh size as explained in Sect. 3.4.1. Tensile strength comes from material testing. However, the experimental work carried out in this study only gave values for compressive strength, whereas the FE model's failure 
load was mostly influenced by tensile strength. Therefore, a relationship between compressive and tensile strengths was assumed based on the literature, and sensitivity analysis was carried out, to find the best suited value of this parameter as explained in Sect. 3.4.

\subsubsection{Effect of Mesh Size}

To evaluate the effect of mesh size on the results of FE model, three different sizes of mesh were considered for unplastered FE model M1- $(U)$ and divided into two categorises with reference to proposed mesh (medium mesh $30 \mathrm{~mm}, 25 \mathrm{~mm}$ and $37.5 \mathrm{~mm}$ in $x, y$ and $z$ direction, respectively) in Sect. 2. One alternative is fine mesh, which employs elements half those of medium mesh with a size of $15 \mathrm{~mm}, 12.5 \mathrm{~mm}$ and $18.75 \mathrm{~mm}$ in $x, y$ and $z$ directions, respectively. The second alternative is coarse mesh, with elements twice the size of the medium mesh, with a size of $60 \mathrm{~mm}, 50 \mathrm{~mm}$ and $75 \mathrm{~mm}$ in $x, y$ and $z$, respectively. The outcome of the sensitivity analysis is shown in Fig. 11. It can be observed that the medium mesh best suits the experimental results for unplastered column, whereas fine and coarse mesh overestimate the peak load and grossly overestimate the stiffness of the model. This is due to the fracture energy $G_{\mathrm{f}}$ as the same values of fracture energy $G_{\mathrm{f}}$ are used for three types of mesh which is required to be adjusted with the size of mesh. $G_{\mathrm{f}}$ values are obtained from Eq. 1, and this will vary depending on the size of mesh and will be considered in the future studies. Equation 1 is related to crack band width $\mathrm{h}$ parameter. In this study, h parameter has been fixed for all types of mesh in sensitivity analysis. In reality, h value should be analysed and should be considered in future work. Both linear and nonlinear behaviours for the block and interface were considered; however, the block was always found within linear behaviour and nonlinear behaviour only observed in interface as it reached max elastic strength earlier than block.

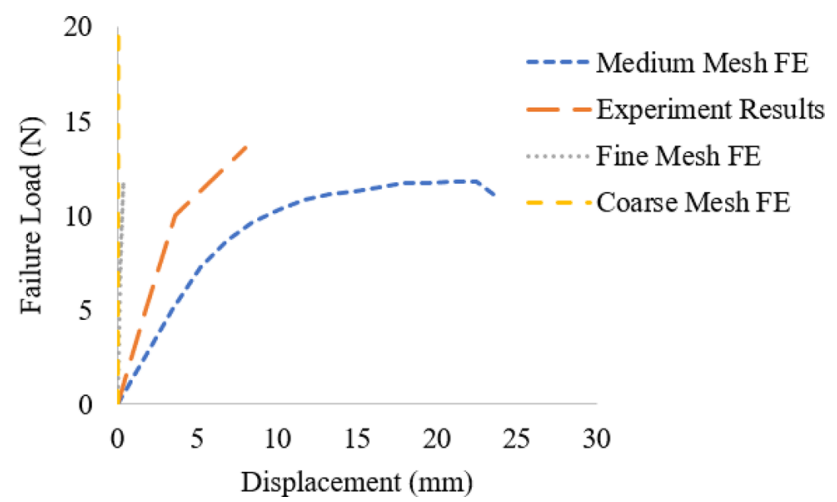

Fig. 11 Effect of mesh size on the results of FE model

\subsubsection{Tensile Strength Effect}

An extensive testing was carried out by [27] for the tensile strength of clay units and proposed a ratio between the tensile and compressive strength which ranges from 0.30 to 0.10 . Similarly, for the plaster, a ratio of 0.10 was considered in many studies $[16,28]$. No further tensile testing was carried out in this study, and $10 \%$ of compressive strength was selected. Trial values of this ratio were tested to identify the best value of tensile strength of block and plaster. It was found that model with tensile strength equal to $10 \%$ compressive strength gave the best results comparable to experimental results.

\section{Parametric Study}

The following sections detail the parametric study of varying three main parameters, namely the compressive strength of block, compressive strength of plaster and thickness of plaster. In order to investigate the effect of these parameters, only one parameter was varied at a time and the values of other parameters remained unchanged in the FE models. A similar method was adopted by other researchers like $[12,29]$.

\subsection{Strength of Block}

Three values of block compressive strength were considered for parametric study. The value of $0.83 \mathrm{MPa}$ was considered from the experimental work by [23] of mortar-free interlocking blocks. The other two values of $2.5 \mathrm{MPa}$ and $5.42 \mathrm{MPa}$ were found in different research studies for stabilised soil blocks [30, 31]. The unplastered model $(\mathrm{M} 1-U)$ was used to identify the effect of block compressive strength, and the outcome is shown in Fig. 12. It can be observed that loadcarrying capacity of the ISSB column was increased with an increase in compressive strength. The failure load was

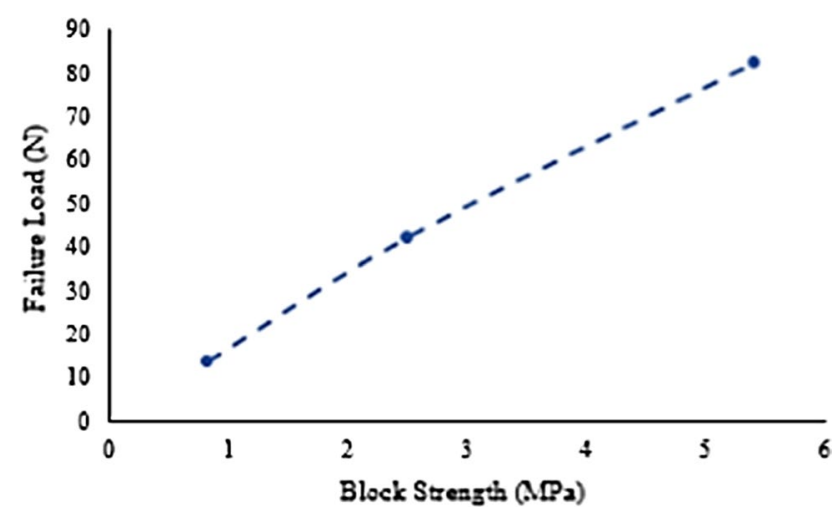

Fig. 12 Effect of block strength on unplastered failure load (FE modelling) 
increased to $83 \mathrm{~N}$ from $15 \mathrm{~N}$ with an increase in compressive strength from 0.83 to $5.42 \mathrm{MPa}$. However, in experimental work, failure was observed in the interface between blocks and compressive strength of block is not found as governing mode of failure.

\subsection{Strength of Plaster}

Three values of compressive strength of plaster were considered for parametric study. The values of compressive strength of each cube sample (plain, rice straw and sisal fibrous plaster) evaluated from experimental work were chosen as the initial values for each model. The other two values were chosen from the literature review where most commonly the values of $29 \mathrm{MPa}$ and $41 \mathrm{MPa}$ were found $[32,33]$. A total of 18 FE models were produced by keeping all other parameters constant except for the compressive strength of plaster. The outcome of the parametric study is shown in Fig. 13. It can be observed that in almost all cases there is no change in the failure load with the increase in compressive strength of plaster. The reason for this, as identified earlier in Sect. 3, was namely that the interface between the plaster and block was the governing failure mechanism. Therefore, increasing the compressive strength of plaster did not result in increase in failure load. Secondly, the change in tensile strength is based on compressive strength; however, the change in tensile strength is negligible; therefore, no effect was found on the results.

\subsection{Thickness of Plaster}

Three values of thickness of plaster $8 \mathrm{~mm}, 12 \mathrm{~mm}$ and $20 \mathrm{~mm}$ were considered to observe the effect on failure load. In total, nine FE model was produced by keeping all other parameters constant, except for the thickness of plaster. The results of parametric analysis are shown in Fig. 14.

It can be observed there is $77 \%$ increase in failure load for the plain-plastered column after increasing the thickness of

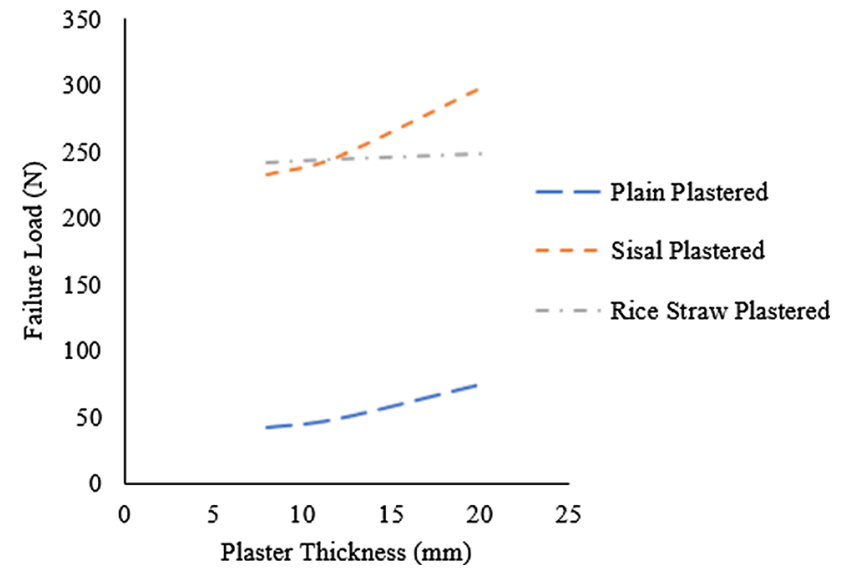

Fig. 14 Effect of plaster thickness on failure load graph

plaster by factor of 2.5. For the fibrous sample, it was noted that a similar increase in thickness of plaster only gave $28 \%$ improvement in failure load.

\section{Cost Analysis and Practical Application}

From experimental and numerical analysis, it was found that addition of fibrous plastering to the tension face of columns enhanced the peak lateral load and other mechanical properties such as elastic stiffness, pre- and post-crack energy absorption and toughness. However, addition of plaster and fibres to one face will increase the overall construction cost. In order to reduce the construction cost of the wall in practical application, the thickness of the wall (i.e. thickness of blocks) could be reduced. Finite element sensitivity analysis was carried out to find the equivalent thickness of fibrous plastered column to an unplastered column having similar or better lateral resistance. An unplastered unmortared column of $150 \mathrm{~mm}$ thickness was taken as datum. Plain- and fibrousplastered walls with mortar and interlock were compared to
Fig. 13 Effect of plaster strength on failure load graph

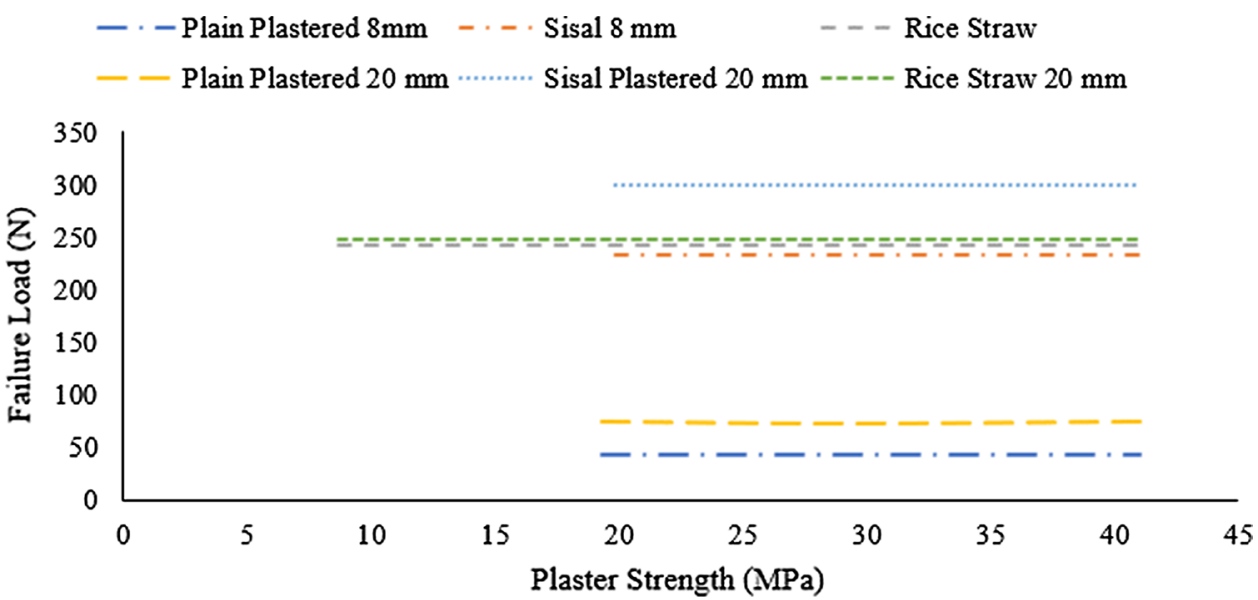


find this equivalent thickness. The following variations were considered as detailed below:

A. (Datum) Unmortared, unplastered column of thickness $150 \mathrm{~mm}$.

B. Unmortared, plain-plastered column of block thickness $x$ (plus $8 \mathrm{~mm}$ plaster).

C. Unmortared, fibrous-plastered column of block thickness $y$ (plus $8 \mathrm{~mm}$ plaster).

D. Mortared, unplastered wall of block thickness $z$.

\subsection{Sensitivity Analysis and Results}

Sensitivity analysis was carried out using hit and trial method of reducing the block thickness in the models B, $\mathrm{C}$ and $\mathrm{D}$ until their lateral resistance was equal to that of datum model A. Results are detailed in Table 10: $(25 \mathrm{~mm}$ was considered to be the minimum theoretical block thickness). $25 \mathrm{~mm}$ thickness may not be practically possible, but this gives a range to reduce the thickness of block to reasonable practical value between 25 and $150 \mathrm{~mm}$.

It can be observed from the results (Table 10) that in both cases (B and C) of unmortared masonry column, a 25-mmthick column with 8 -mm plaster gave better lateral resistance than the unmortared unplastered $150 \mathrm{~mm}$ datum.

\subsection{Cost Comparison}

Based on the above results, cost of construction of $1 \mathrm{~m}^{2}$ of walling was calculated for the various options. It can be observed that a $67 \%$ cost saving could be achieved by reducing the wall thickness to $25 \mathrm{~mm}$ for the examples $\mathrm{B}$ and C. They will have better lateral resistance than datum A (Table 11).

\section{Conclusion}

The aim of this numerical work was to develop NLFE predictive tools to firstly identify a likely failure mechanism (e.g. bond failure) compatible with the experimental work and secondly to do parametric studies more cheaply than via constructing many walls. 3D nonlinear FE models of
Table 11 Comparison of cost

\begin{tabular}{lllll}
\hline Type & A-Datum & $\begin{array}{l}\text { B-thick- } \\
\text { ness } \\
25 \mathrm{~mm}\end{array}$ & $\begin{array}{l}\mathrm{C}-\text { thick- } \\
\text { ness } \\
25 \mathrm{~mm}\end{array}$ & $\begin{array}{l}\mathrm{D}- \\
150 \mathrm{~mm} \\
\text { thickness }\end{array}$ \\
\hline Cost $(\$) / \mathrm{m}^{2}$ & 3.52 & 1.15 & 1.16 & 5.90 \\
$\begin{array}{l}\text { Normalized to } \\
\text { unmortared }\end{array}$ & 1.00 & 0.33 & 0.33 & 1.68 \\
$\begin{array}{l}\text { unplastered wall } \\
\text { (A) }\end{array}$ & & & & \\
\hline
\end{tabular}

unplastered, plain-plastered and fibrous-plastered columns made of mortar-free interlocked blocks were developed. The FE models were validated using the experimental results of this study. The FE model represented the block and plaster with eight-node isoparametric solid brick elements. For the interface between block and plaster, eightnode interface elements were used. The adopted geometrical and material properties were either obtained from the experimental work as a part of this study or calculated based on well-used models. The solution method was adopted based on an incremental iterative procedure using displacement increments of $0.1 \mathrm{~mm}$ for 20 steps. Failure behaviour was verified by comparing the FE models failure load, load displacement curves and crack patterns to the experimental results. Based on the comparative results between FE models and experimental results, the following conclusions were obtained.

- Lateral failure loads from FE models were in fair agreement with the experimental results. The average experimental and FE failure lateral load ratios obtained were 1.0, 1.07, 1.00 and 1.04 for unplastered, plain-plastered, rice-straw-reinforced plaster and sisal-plastered columns, respectively. This has validated the FE models and can be used for further analysis.

- The load-displacement curves showed that the stiffness of the FE model was markedly higher than the experimental results for the first stage of crack formation. This could be due to assumptions for constraint conditions being fixed in FE model. Once the crack forms, the failure load was comparable between the FE values and
Table 10 Failure load sensitivity analysis for equivalent thickness

\begin{tabular}{llll}
\hline Model & $\begin{array}{l}\text { Fz }(N) \text { with } \\
\text { 150-mm block } \\
\text { thickness }\end{array}$ & $\begin{array}{l}\text { Fz }(N) \text { with } \\
\text { reduced block } \\
\text { thickness }\end{array}$ & Reduced thickness of block \\
\hline A-Unmortared unplastered (Datum) & 27.36 & - & - \\
B-Unmortared plain-plastered & 137.54 & 35.8 & $25 \mathrm{~mm}+8 \mathrm{~mm}$ plaster \\
C-Unmortared fibrous-plastered & 167.7 & 45.4 & $25 \mathrm{~mm}+8 \mathrm{~mm}$ plaster \\
D-Unplastered but Mortared & 208 & - & - \\
\hline
\end{tabular}


experimental results, because of the rotational smeared crack model.

- The FE models crack patterns have a good agreement with the crack patterns observed in the experimental tests, e.g. the opening of joints for unplastered columns and cracking in the interface between plaster and block for plastered ones. This showed most emphasis is required to increase the strength of interface for an overall increase in lateral resistance.

- Parametric study of block strength has shown that the failure load is directly proportional to the compressive strength of masonry blocks. Failure of blocks was not found to be a governing failure mode in experimental work.

- Parametric studies suggest that increasing the strength of plaster does not change the failure load. This is because failure is initiated by cracks in the interface between plaster and block. Also plaster contribution is expected in the tensile zone rather than compressive.

- Parametric study for thickness of plaster showed that increase in thickness of plaster resulted in the increase in failure load, but this increase is not linear with the increase in thickness of plaster, e.g. a $150 \%$ increase in thickness of plaster only resulted in $28 \%$ increase in failure load.

- Column thickness can be reduced to $25 \mathrm{~mm}$ of blocks with $8 \mathrm{~mm}$ of plaster and yet exceed the lateral strength of a 150-mm-thick unplastered column.

- Cost comparison showed that fibrous-plastered with $25 \mathrm{~mm}$ thickness gave equivalent performance to the 150-mm-thick unplastered column with $67 \%$ cost saving.

Nonlinear finite element modelling of interlocked masonry column was carried and validated using the experimental results. Based on validated models, parametric study was carried out. The results showed the potential use of fibrous plaster in the tension face of interlocked masonry and improved performance to lateral loading. Finite element modelling suggested in this study for interlocked masonry is a first step to develop the use of interlocked masonry further. The cost saving could be achieved by reducing thickness of blocks to a reasonable practical value, and at the same time lateral strength could be increased by the additional of plaster. The results also showed more emphasis is required in the strength of interface between block and plaster. Based on the outcome of finite element modelling of this study, NLFE models could be extended to $2200 \mathrm{~mm}$ high walls connected with roof truss and $8 \mathrm{~mm}$ fibrous plaster to explore the overall performance of masonry walling in future works. These models could be subjected to seismic loading, and performance of masonry interlocked walling could be evaluated without expensive field testing.
Acknowledgements The authors would like to thank organizations who helped them throughout this research work which was funded by Energy and Low-Income Tropical Housing Project (ELITH). The careful review and constructive suggestions by the anonymous reviewers are gratefully acknowledged.

Author contributions FQ was involved in methodology, data extraction, modelling, writing — original draft; SQ was involved in supervision, review and editing.

\section{Compliance with Ethical Standards}

Conflict of interest The authors declare that they have no known competing financial interests or personal relationships that could have appeared to influence the work reported in this paper.

Open Access This article is licensed under a Creative Commons Attribution 4.0 International License, which permits use, sharing, adaptation, distribution and reproduction in any medium or format, as long as you give appropriate credit to the original author(s) and the source, provide a link to the Creative Commons licence, and indicate if changes were made. The images or other third party material in this article are included in the article's Creative Commons licence, unless indicated otherwise in a credit line to the material. If material is not included in the article's Creative Commons licence and your intended use is not permitted by statutory regulation or exceeds the permitted use, you will need to obtain permission directly from the copyright holder. To view a copy of this licence, visit http://creativecommons.org/licenses/by/4.0/.

\section{References}

1. Giamundo, V.; Lignola, G.P.; Prota, A.; Manfredi, G.: Nonlinear analyses of adobe masonry walls reinforced with fiberglass mesh. Polymers 6(2), 464-478 (2014)

2. Giamundo, V.; Sarhosis, V.; Lignola, G.P.; Sheng, Y.; Manfredi, G.: Evaluation of different computational modelling strategies for the analysis of low strength masonry structures. Eng. Struct. 73, 160-169 (2014)

3. Askouni, P.D.; Papanicolaou, C.C.G.: Role of mortar joints in textile reinforced mortar-to-masonry bond. J. Compos. Constr. 24(6), 04020069 (2020)

4. Ceronia, F.; Leoneb, M.; Rizzob, V.; Bellinic, A.; Mazzotti, C.: Influence of mortar joints on the behaviour of FRP materials bonded to different masonry substrates. Eng. Struct. 153, 550-568 (2017)

5. Mohamad, G.; Lourenco, P.B.; Roman, H.R.: Mechanics of hollow concrete block masonry prisms under compression: review and prospects. Cem. Concr. Compos. 29(3), 181-192 (2007)

6. Khonsari, S.V.; Eslami, E.; Anvari, A.: Fibrous and non-fibrous Perlite concretes - experimental and SEM studies. Eur. J. Environ. Civ. Eng. 22(2), 138-164 (2018)

7. Çaktı, E.; Saygıll, Ö.; Lemos, J.V.; Oliveira, C.S.: Discrete element modeling of a scaled masonry structure and its validation. Eng. Struct. 126, 224-236 (2016)

8. Noor-E-Khuda, S.; Dhanasekar, M.: Masonry walls under combined in-plane and out-of-plane loadings. J. Struct. Eng. (U.S.) 144(2), 96 (2018)

9. Parisi, F.; Lignola, G.P.; Augenti, N.; Prota, A.; Manfredi, G.: Nonlinear behavior of a masonry subassemblage before and after strengthening with inorganic matrix-grid composites. J. Compos. Constr. 15(5), 821-832 (2011) 
10. Scordelis, A.C.; Ngo, D.: Finite element analysis of reinforced concrete beams. J. Am. Concr. Inst. 64(14), 152-163 (1967)

11. Rots, J.G.; Blaauwendraad, J.: Crack models for concrete: discrete or smeared? Fixed multi-directional or rotating. BibSonomy 34(1), 3-59 (1989)

12. Qapo, M.; Dirar, S.; Yang, J.; Elshafie, M.: Nonlinear finite element modelling and parametric study of CFRP shear-strengthened prestressed concrete girders. Constr. Build. Mater. 76, 245-255 (2015)

13. Sarhosis, V.; Garrity, S.W.; Sheng, Y.: Influence of brick-mortar interface on the mechanical behaviour of low bond strength masonry brickwork lintels. Eng. Struct. 88, 1-11 (2015)

14. Basili, M.; Marcari, G.; Vestroni, F.: Nonlinear analysis of masonry panels strengthened with textile reinforced mortar. Eng. Struct. 113, 245-258 (2016)

15. Soto Izquierdo, I.; Soto Izquierdo, O.; Ramalho, M.A.; Taliercio, A.: Sisal fiber reinforced hollow concrete blocks for structural applications: testing and modeling. Constr. Build. Mater. 151, 98-112 (2017)

16. Lignola, G.P.; Prota, A.; Manfredi, G.: Numerical investigation on the influence of frp retrofit layout and geometry on the in-plane behavior of masonry walls. J. Compos. Constr. 16(6), 712-723 (2012)

17. Lignola, G.P.; Prota, A.; Manfredi, G.: Nonlinear analyses of tuff masonry walls strengthened with cementitious matrix-grid composites. J. Compos. Constr. 13(4), 243-251 (2009)

18. Qamar, F.; Thomas, T.; Ali, M.: Assessment of mechanical properties of fibrous mortar and interlocking soil stabilised block (ISSB) for low-cost masonry housing. Mater. Constr. 69(336), e201 (2019)

19. Schubert, P.: The influence of mortar on the strength of masonry. Brick Block Mason. 1-3, 162-174 (1988)

20. Phillips, D.V.; Zhang, B.S.: Direct tension tests on notched and un-notched plain concrete specimens. Mag. Concr. Res. 45(162), 25-35 (1993)

21. Dirar, S.; Lees, J.; Morley, C.: Precracked reinforced concrete t-beams repaired in shear with bonded carbon fiber-reinforced polymer sheets. ACI Struct. J. 109(2), 215-223 (2012)

22. Sato, Y.; Vecchio, F.J.: Tension stiffening and crack formation in reinforced concrete members with fiber-reinforced polymer sheets. J. Struct. Eng. ASCE 129(6), 717-724 (2003)
23. Qamar, F.; Thomas, T.; Ali, M.: Use of natural fibrous plaster for improving the out of plane lateral resistance of mortarless interlocked masonry walling. Constr. Build. Mater. 174, 320-329 (2018)

24. Bejarano-Urrego, L.; Verstrynge, E.; Giardina, G.; Van Balen, K.: Crack growth in masonry: numerical analysis and sensitivity study for discrete and smeared crack modelling. Eng. Struct. $\mathbf{1 6 5}$, 471-485 (2018)

25. Dirar, S.; Lees, J.M.; Morley, C.T.: Precracked reinforced concrete T-beams repaired in shear with prestressed carbon fiber-reinforced polymer straps. ACI Struct. J. 110(5), 855-865 (2013)

26. Hee, S.C.; Jefferson, A.D.: A new model for simulating cracks in cementitious composites. Proc. Inst. Civ. Eng. Eng. Comput. Mech. 161(1), 3-16 (2008)

27. Prota, A.; Marcari, G.; Fabbrocino, G.; Manfredi, G.; Aldea, C.: Experimental in-plane behavior of tuff masonry strengthened with cementitious matrix-grid composites. J. Compos. Constr. 10(3), 223-233 (2006)

28. Stratford, T.; Pascale, G.; Manfroni, O.; Bonfiglioli, B.: Shear strengthening masonry panels with sheet glass-fiber reinforced polymer. J. Compos. Constr. 8(5), 434-443 (2004)

29. Qin, S.: Shear behaviour of corroded reinforced concrete t-beams repaired with fibre reinforced polymer systems. Ph.D. Thesis, University of Birmingham, UK (2016)

30. Anand, K.B.; Ramamurthy, K.: Development and performance evaluation of interlocking-block masonry. J. Archit. Eng. 6(2), 45-50 (2000)

31. Fundi, S.I.; Kaluli, J.W.; Kinuthia, J.: Performance of interlocking laterite soil block walls under static loading. Constr. Build. Mater. 171, 75-82 (2018)

32. Zych, T.; Wojciech, K.: Study on the properties of cement mortars with basalt fibres. In: Brandt, A.M.; Olek, J.; Glinicki, M.A.; Leung, C.K.Y. (Eds.) Brittle Matrix Composites 10, pp. 155-166. Woodhead Publishing, Cambridge (2012)

33. Lertwattanaruk, P.; Suntijitto, A.: Properties of natural fiber cement materials containing coconut coir and oil palm fibers for residential building applications. Constr. Build. Mater. 94, 664669 (2015) 